\title{
EL CUESTIONAMIENTO DEL MATERIALISMO EN TORQUEMADA EN LA HOGUERA DE BENITO PÉREZ GALDÓS María Luisa Pérez Bernardo*
}

RESUMEN: Benito Pérez Galdós es considerado, después de Cervantes, como el mejor escritor de la literatura española y el más eminente del siglo XIX. Las novelas galdosianas abordan una toma de posición frente a unas situaciones y problemas ideológicos determinados. En su novela Torquemada en la hoguera, Galdós revela la incapacidad del usurero para comprender la realidad, para elevarse por encima de la codicia y avidez. Personifica el eje materialista, el alma monetaria de la filosofía vital de la burguesía española de ese siglo.

$$
\text { sose }
$$

THE QUESTIONING OF MATERIALISM IN TORQUEMADA EN LA HOGUERA BY BENITO PÉREZ GALDÓS

ABSTRACT: Benito Pérez Galdós is considered the best author of all Spanish literature after Cervantes, and he has been recognized as the best writer of the 19th century. Galdós's novels are analyses of social trends and problems that lay at the heart of nineteenth-century civilization. In Torquemada en la hoguera, Galdós reveals the usurer's inability to comprehend reality, to rise over lust and greed. Torquemada embodies the materialist core and the monetary soul of a vital philosophy from the Spanish merchant class of that century.

PALABRAS CLAVE: clase media, realismo literario, usura.

KEY WORDS: literary realism, middle-class society, usury.

RECEPCIÓN: 4 de diciembre de 2017.

APROBACIÓN: 5 de octubre de 2018.

DOI: $10.5347 / 01856383.0129 .000294414$

* Departamento de Lenguas Modernas, Universidad de Dallas. 
Se prohíbe su reproducción total o parcial por cualquier medio, incluido electrónico, sin permiso previo y por escrito de los editores. 


\section{EL CUESTIONAMIENTO \\ DEL MATERIALISMO \\ EN TORQUEMADA EN \\ LA HOGUERA DE \\ BENITO PÉREZ GALDÓS}

\section{Introducción}

Benito Pérez Galdós (1843-1920) fue el principal líder de la generación de escritores de la Revolución de 1868, un grupo que encontró particularmente en la novela el medio para canalizar la búsqueda de nuevos valores y su crítica a los problemas existentes. Como bien ha señalado Lina Rodríguez Cacho, Galdós, al igual que Clarín y Valera, adoptó la oposición a la concepción absolutista del Estado, la defensa del libre pensamiento, la conciliación entre una fe de gran capacidad emotiva y la razón para darle sentido a la religión en el progreso de la humanidad, una ética sostenida por la virtud de la honestidad y opuesta a toda manifestación de hipocresía y, sobre todo, la confianza en el poder de la educación para cambiar las costumbres sociales. ${ }^{1}$ Equivalente directo de Balzac en España, con el que lo unen vínculos decisivos, pasó su vida alimentando la ola torrencial de una producción de más de ciento diez volúmenes de obras. Sus aportaciones tienen tan gran peso en el devenir de la novela española, que es imposible reducir su gigantesca obra a uno solo de los moldes que configuran esta novelística.

${ }^{1}$ Lina Rodríguez Cacho, Manual de historia de la literatura española. Siglos XVIII al XX, 2009, Madrid, Castalia, p. 184. 
La narrativa galdosiana no solo cubre por completo el último tercio del XIX, sino que aparece ante nuestros ojos como cabeza o representante principal de algunas de sus tendencias esenciales. Por medio de estas, se nos muestran las conmociones del siglo, generadoras de una movilidad sin precedente de las condiciones y conductas, así como los nuevos términos que plantean la representación de la existencia. En sus novelas, Galdós saca a la luz la historia percibida como una lucha entre las fuerzas abstractas, encarnadas por individuos o grupos creados bajo el imperio de las circunstancias. De esto resulta un dualismo polémico, de finalidad política declarada, que se detiene y luego se borra con brusquedad alrededor de 1880. Sabido es que el propio Galdós conoció e investigó escrupulosamente la historia de la España decimonónica y que, en su empresa reformadora de la novela de la época, la concibió como un instrumento de observación y reprobación de la sociedad contemporánea.

Una de esas novelas, Torquemada en la hoguera (1889), ${ }^{2}$ se centra en la figura de un usurero sometido a crueles desgarramientos afectivos y que presenta desde un punto de vista impresionista - muy revelador de las orientaciones del momento- a uno de los actores esenciales de la burguesía española pintada a lo largo de la década de 1880. El autor canario enlaza su personaje con una saga de usureros de ficción: Shylock de William Shakespeare, ${ }^{3}$ Harpagón de Molière, Scrooge de Charles Dickens y Elena Ivanova de Fiódor Dostoievski. Lo más curioso es que el escritor elige el nombre de Torquemada, emparentando al nuevo avaro con el famoso dominico del mismo apellido, Tomás de Torquemada, el gran inquisidor que llevó a cabo la persecución de judeoconversos entre 1480 y 1530 . El inquisidor quemaba herejes, mientras que el Torquemada de Galdós quema deudores. Así se muestra gráfica y cómicamente

${ }^{2}$ La tetralogía de las novelas de Torquemada se publicó entre 1889 y 1895: Torquemada en la hoguera (1889), Torquemada en la cruz (1893), Torquemada en el purgatorio (1894) y Torquemada y San Pedro (1895).

${ }^{3} \mathrm{Al}$ poco tiempo de componer Torquemada en la hoguera, Galdós visitó Italia. Allí en Venecia comenzó a reflexionar sobre las obras de Shakespeare; y sus pensamientos se expresan en la carta publicada en La Prensa el 18 de enero de 1889. En dicha carta, Galdós escribió lo siguiente: "El tipo de judío Shylock del Mercader de Venecia, es, no obstante, universal, fanático, implacable con el acreedor, vengativo, odia a Antonio que es cristiano y porque presta sin interés". Ni que decir que hay un paralelo entre este personaje y Torquemada, que en la futura novela adquiere el título de judío. 
la confusión económico-ideológica de la época: el ídolo del dinero se ha elevado a la categoría de lo religioso. Además, el nombre de Francisco nos recuerda al santo italiano, pero al contrario de la vida austera y simple que llevaba el fraile, nuestro personaje es justamente lo opuesto: un prestamista que ha logrado amasar un cuantioso capital a base de prestar con usura, exprimiendo sin piedad a los más pobres y desvalidos.

\section{Torquemada en la hoguera ${ }^{4}$}

Por mucho que Galdós, espíritu abierto y libre, rechazara - como rechazó con ironía - las posiciones doctrinales y el programa sociológico-literario de los naturalistas, no deja sin embargo de aplicarse con clara deliberación al estudio de la sociedad. Nuestro autor quería mostrar que la clase media estaba llegando, o acaso había llegado ya, a ser protagonista de la historia nacional, y que a él le correspondía ser su cronista y su crítico, interesado en el proceso estabilizador que, dentro de los postulados democráticos y liberales, debía cumplir esa clase. La conquista y la ocupación de la novela significaron un encuentro y una búsqueda trascendentales: el hallazgo de una temática y el intento de apropiarse de un arte de narrar. Por lo que hace a lo primero, el terreno social era más que propicio y Galdós lo había acotado bien al fijar su mirada en las anchas capas urbanas que se dilataban entre la aristocracia, la burguesía, la clase media y el pueblo. Además, y como bien ha indicado Gustavo Correa, se sumerge cada vez más en una dimensión de profundidad que abarca lo múltiple de la criatura humana en sus más variadas manifestaciones y dentro de las cuales se hallan los fenómenos de la conciencia individual: "El realismo de Galdós se dirige, de esta manera, hacia una exploración de la persona como centro irradiante de comunicación con el mundo exterior". ${ }^{5}$ Existe, por tanto, la inevi-

${ }^{4}$ Torquemada en la hoguera se escribió ex profeso para la importante revista cultural La España Moderna (1889-1914), por la insistencia del director José Lázaro Galdiano. A cambio, recibió el autor un dibujo de Goya y 150 pesetas, pago nada excepcional, pero respetable para esa época.

${ }^{5}$ Gustavo Correa, El simbolismo religioso en las novelas de Pérez Galdós, 1962, Madrid, Gredos, p. 11. 
table interacción entre personaje y medio ambiente, la cual constituye uno de los postulados esenciales del realismo del siglo XIX. Sin embargo, aun dentro de este supuesto fundamental, el hombre se halla en el mundo novelístico en condiciones de poder amoldar su propia vida y, en cierto modo, de someter la realidad externa con la firmeza y heroicidad de su propia voluntad.

La serie de Torquemada corresponde al periodo denominado por Galdós de las “novelas contemporáneas". En estas obras se produce un cruce entre el hecho histórico y el discurso novelesco, procedimiento que permite indagar no solo en el alma individual y sus conflictos, sino también en el acceso a una realidad que es depositaria de la relación entre vida y ficción, espejo e irrealidad. En estas novelas escritas a finales de siglo, como bien observa Michael Predmore, se anuncia y se revela progresivamente que la "gran clase media" en que Galdós había puesto sus esperanzas, fracasó en su función histórica de conseguir las metas y objetivos de la Revolución de $1868 .{ }^{6}$ En Torquemada en la hoguera surge la estampa e imagen de un hombre que se personifica narrativamente en un trozo de la vida de Francisco Torquemada y la historia de una familia, los Águila. En este sentido, los títulos de las novelas, con su simbología religiosa, inducen a realizar una lectura que articule las voces de las víctimas y mártires que recorren la acción novelesca por medio de la escritura.

Si el tema del avaro es central a la serie de Torquemada, tal tema se estructura también, como todo, a partir de una historia social que no solo aparece reproducida en la novela, sino que es determinante de la narrativa. Lo primero que hace el narrador es sentar las bases para el reconocimiento de la personalidad, las actividades y la situación histórica del personaje a cuya "quema" vamos a asistir. Importa notar que la causa de su distinción no es psicológica, sino muy precisamente, histórico-general: se nos explica enseguida que tal vez Torquemada "habría sido así en otra época; pero no pudo eximirse de la influencia de esta segunda mitad del siglo XIX, que casi ha hecho una religión de las

${ }^{6}$ Michael Predmore, “Alegoría política y moral en Torquemada en la hoguera”, en Estudios de literatura, cultura e historia contemporánea, 2014, Madrid, Ediciones de la Universidad Autónoma de Madrid, pp. 103-120. 
materialidades decorosas de la existencia". ${ }^{7}$ En la relación de los cambios perceptibles que fue experimentando el usurero y su familia en estos años hay, a través de los comentarios del narrador, una interpretación tanto del texto como de la circunstancia histórica. El crítico Blanco Aguinaga ha constatado cómo el ascenso de nuestro personaje, un miserable emigrante a la ciudad que se convierte en usurero, financiero, senador y marqués equivale, en forma extrema o ejemplar, al ascenso al poder de la burguesía española a lo largo del XIX. ${ }^{8}$ El mejoramiento social de la familia Torquemada se ejemplifica en estas palabras del narrador: "En fin, que pasito a paso y a codazo limpio, se habían ido metiendo en la clase media, en nuestra bonachona clase media, toda necesidades y pretensiones, y que crece tanto, tanto, jay dolor! que nos estamos quedando sin pueblo". ${ }^{9}$ La explicación histórica sigue desarrollándose cuando leemos que se trata "de la época que arranca de la desamortización". ${ }^{10}$ Efectivamente, asistimos a una ascensión social promovida por la confiscación de las tierras de la Iglesia, ${ }^{11}$ que transforma al antiguo usurero en influyente financiero, al tiempo que desarrolla su función regeneradora de una aristocracia decadente convertida al positivismo materialista en el marco político de la Restauración.

La actitud de censura que manifiesta Galdós ante este personaje es una clara muestra de su particular desacuerdo con el comportamiento de la clase media, que pierde su identidad en aras de una ambición que viene a instrumentalizar a todo aquello que se interpone y dificulta su objetivo. La obsesión por alcanzar a toda costa un ascenso social, al menos ante los ojos de los demás, se manifiesta a través de unos signos que se multiplican en el seno de una ciudadanía jerarquizada en la que

${ }^{7}$ Benito Pérez Galdós, Las novelas de Torquemada, 1970, Madrid, Alianza, p. 12.

${ }^{8}$ Carlos Blanco Aguinaga, "La determinación social de Torquemada", en Historia y crítica de la literatura española. Romanticismo y realismo, 1994, Barcelona, Crítica, p. 534.

${ }^{9}$ Benito Pérez Galdós, Las novelas de Torquemada, p. 8.

${ }^{10}$ Ibid., p. 13.

${ }^{11}$ La desamortización española fue un largo proceso histórico, económico y social iniciado a finales del siglo XVIII con la llamada "Desamortización de Godoy" (1798) y que tuvo varias etapas a lo largo del siglo XIX. Consistió en sacar a subasta pública, previa expropiación forzosa por parte del Estado, los bienes y tierras de la Iglesia y de las órdenes religiosas. Desde el punto de vista estrictamente social fracasó: la división de los lotes de tierra se encomendó a comisiones municipales y estas, aliadas con los oligarcas adinerados, manipularon el sistema. 
son frecuentes las actitudes hidalgas; en una sociedad que va adquiriendo un perfil liberal pero que está muy lejos de ser democrática. En cuanto a tipo, como bien señala el crítico García Sarriá, Torquemada es representativo de la sociedad de su tiempo, es una "síntesis negativa de su época, una figura colectiva del siglo XIX, que concretamente acumula dinero y representa los intereses creados de la clase media española", ${ }^{12} \mathrm{y}$ Teresa Fuentes Peris ha observado que el personaje es: "the embodiment of a spirit of utility and profit, a concept arising from the new ideology of economic liberalism that challenged the waste and inefficiency". ${ }^{13}$

Efectivamente, el fondo histórico es la Revolución Gloriosa de 1868, y sirve irónicamente para contrastar las variantes político-liberales con la constante ascensión económica del usurero:

Torquemada empezó a usar chisteras de cincuenta reales; disfrutaba de dos capas; una muy buena, con embozos colorados, los hijos iban bien apañaditos; Rufina tenía un lavabo de los de mírame y no me toques, con jofaina y jarro de cristal azul [...]; doña Silvia se engalanó con un abrigo de pieles que parecía de conejos [...]; en fin, que pasito a paso y a codazo limpio, se habían ido metiendo en la clase media. ${ }^{14}$

El ascenso de este hombre a través de los diferentes estratos sociales hasta llegar a la cumbre implica una serie de cambios. Torquemada presenciará con horror "el nuevo orden de las cosas" que se impone en su vida; un nuevo orden que se manifiesta en una oleada de signos indicativos de la nueva posición social. En el fondo, no es que el protagonista actúe solo como un tirano que hace de la materialidad un modo de existencia, sino que la religión del dinero lo convierte en instrumento y víctima de sus propios deseos y pasiones. Vale decir que la predicación del sujeto tacaño tiene que ver con el dominio que lo material realiza sobre su persona. Él es un ser encarcelado en el lenguaje materialista de la codicia. Más que victimario, termina siendo víctima de

${ }^{12}$ Francisco García Sarriá, "El plano alegórico de Torquemada en la hoguera”, en Anales Galdosianos, 15 (1980), p. 103.

${ }^{13}$ Teresa Fuentes Peris, Galdós's Torquemada novels: Waste and profit in late nineteenthcentury Spain, 2007, Cardiff, University of Welsh Press, p. 17.

${ }^{14}$ Las novelas de Torquemada, pp. 13-14. 
los designios irrecusables de una "religiosidad inquisidora", en la que lo que predomina es el dinero, los negocios y las transacciones.

Pero como castigo a la avaricia de Torquemada, su único y amado hijo se verá afectado por una mortal enfermedad. Al comienzo del capítulo IV se muestra abiertamente la gravedad de las dolencias de Valentín: la inflamación del cuerpo. Inmediatamente después, el pensamiento del protagonista se desvela al lector en un largo soliloquio, en el que Torquemada va dando forma a lo que el narrador califica de "pícara idea": que la enfermedad del hijo es un castigo por su usura, y para desagraviar por sus actos trata de reconciliarse con la "humanidad". En sus palabras y en sus pensamientos el lector percibe que no hay ningún sentimiento sincero tras esa actuación, pero en ningún momento el narrador emitirá un juicio sobre este aspecto; dejará que el personaje vaya mostrándose tal cual es. Torquemada, siguiendo los consejos de su amigo Bailón, se convence de que su situación es resultado de la práctica despreciable del oficio de la usura, que tantos sufrimientos provoca a sus pobres deudores. Por tal motivo, intenta reconciliarse con la divinidad realizando obras de caridad y perdonando el pago de sus deudas a la pobre gente de la que se nutre su fortuna. Durante la enfermedad del hijo intenta rectificar su situación frente a Dios; quiere convencer a cuantos le rodean — parientes, víctimas y deudores - de que es semejante a los demás: capaz de amor y sentimiento. El prestamista piensa que de la noche a la mañana, en breve espacio de tiempo, puede cambiar a los ojos del mundo, e incluso, a los de Dios mismo. Desea enmendarse con la práctica de las buenas obras, pero de su corazón solo brota una caridad seca y calculadora. Reparte limosnas ínfimas y no se atreve a dar su capa nueva a un menesteroso que la necesita. Se muestra humano repentinamente con los inquilinos que deben pagarle una renta semanal y regala una cantidad de dinero a un pintor tísico que se muere de hambre. Volviendo Torquemada a su casa tras repartir el dinero entre los pobres que va encontrando, la voz narrativa observa que "Todo ello aceptaba Torquemada menos resignarse. No tenía en su alma la fuente de donde tal consuelo pudiera salir, y ni siquiera lo comprendía". ${ }^{15}$

\section{${ }^{15}$ Ibid., p. 37.}


Pero como siempre, Galdós nos presenta el lado opuesto al usurero, la figura diametralmente en contraposición con Torquemada, la tía Roma, una vieja criada que fielmente ha servido en la casa de don Francisco. La crítica Juana Granado Sánchez ha indicado que esta mujer "no vive su pobreza de un modo marginal, sino con aceptación y plena conciencia de la misma, como una actitud moral y un modo de vida asumido responsable y conscientemente, en aras de una finalidad superior de carácter espiritual". ${ }^{16}$ La penuria del personaje no es resultado de la alienación social y de las estructuras económicas, sino de un rechazo precisamente de esos valores materiales y de la asunción de una vida interior llena de plenitud moral a la que en nada afecta la condición de su miseria. La tía Roma representa un cristianismo primitivo y puro, caracterizado por el desprendimiento total y absoluto de objetos y pertenencias. Es ella la que contrasta el presente y proyecta hacia el futuro del personaje; el diálogo que mantiene con el usurero refleja la conciencia inapelable de la inhumanidad de Torquemada, su hipocresía y su falta de misericordia con los demás. Esa "revelación" de la tía Roma invierte las inercias farisaicas del personaje, dejándolo expuesto ante su verdadera imagen. Las palabras que dirige a Torquemada: "Usted quiere ahora poner un puño en el cielo", ${ }^{17}$ además de ser un sencillo y rápido análisis de la falsa transformación del usurero, adelantan una de las constantes temáticas del resto de la serie: la incapacidad de Torquemada para cambiar moralmente. Tras el fallecimiento de su hijo, el viejo usurero se dedica con renovado ímpetu a sus negocios, a sacar el mayor dinero posible de sus préstamos. La tía Roma sugiere el desenlace del protagonista cuando comenta: "nunca aprende... ya está otra vez preparando los trastos de ahorcar. Mala muerte va usted a tener, condenado de Dios, si no se enmienda". ${ }^{18}$ El hecho de que la vieja hable de "trastos de ahorcar" remite a los utensilios empleados por Tomás de Torquemada para obtener las declaraciones de los judeoconversos, pero

${ }^{16}$ Juana Granado Sánchez, "Guía de lectura de Torquemada en la hoguera de Benito Pérez Galdós”, p. 22, en <http://www.editorialperiferica.com/upload/20101118131525GUI ATORQUEMADA.pdf $>$.

${ }^{17}$ Las novelas de Torquemada, p. 66.

${ }^{18}$ Ibid., p. 73. 
aquí de forma irónica, el que se confiesa es el usurero, reconociendo su culpa, pero no su arrepentimiento. Las últimas palabras de Torquemada revelan su rebelión contra la voluntad divina y la negación absoluta de su sumisión: "Yo hago lo que me da mi santísima gana, so mamarracho, vieja más vieja que la Biblia". ${ }^{19}$ Con esta declaración se muestra con evidencia la personalidad de Torquemada, la avaricia, la cual constituye el eje de su ser. Hay, por lo demás, una relación directa entre esa pasión radical del personaje y su vida espiritual, o más bien, su ausencia de sentimiento religioso. Dicho en otros términos: existe una incompatibilidad de esencia entre su ser avaro y su aptitud para entrar en el ámbito de la vida sobrenatural, o al menos comprenderla, ya que como bien ha señalado Gustavo Correa: "La carencia del amor al prójimo no le permitirá penetrar en la esfera del amor divino. Por el contrario, solo profesa una monstruosa adoración de su propio ego". ${ }^{20}$ Efectivamente, lo que sí ha aprendido Torquemada es que la religión y la filosofía no tienen nada que ver con los asuntos de la vida y la muerte, el premio o el castigo, en la conducta de la vida humana. Se siente absolutamente libre ahora para cultivar su profesión de usurero y financiero, de ganar dinero a expensas de otros, de "hacerle la guerra al pobre" sin el freno de escrúpulos morales y sin miedo a represalias divinas.

En conclusión, Torquemada en la hoguera muestra la confusión del usurero, la idealización del falso ídolo que es el dinero, al que ha adorado siempre, el bienestar material y, lo más triste de todo, el hecho de que confunde la limosna y la caridad con un negocio de compraventa. Él, en su función socioeconómica financiera personifica - exagerada y, por lo tanto, inequívocamente- el eje materialista, el alma monetaria de la filosofía vital de la burguesía española del siglo XIX. Efectivamente, esta incapacidad para afrontar la vida en su totalidad, con sus límites y trabas, es la condición inherente a don Francisco y la causa de su desorientación e incapacidad para elevarse sobre los valores terrenales. Torquemada en la hoguera no supone el aprendizaje de la verdad profunda que subyace en el principio ético del mundo, sino más bien

${ }^{19}$ Loc. cit.

${ }^{20}$ Gustavo Correa, op. cit., p. 139. 
el viaje hacia la desorientación, el vacío y la condenación del individuo. Como contrafigura de Torquemada, el narrador nos presenta a Roma, mujer que representa el principio ético supremo, no ya como teoría, sino como modelo de conducta: una menesterosa que se caracteriza por el amor al prójimo y la solidaridad más humana. Su caracterizante vejez, junto con el nombre-apodo que la identifica, vienen a decirnos que ella simboliza la tradicional y sencilla religión del pueblo español, el cristianismo desnudo de artificios, pompas y galas. De hecho, aunque la mayoría de los críticos han tildado a Galdós de liberal, anticlerical e irreligioso, el escritor canario critica a esa nueva burguesía perteneciente al mundo industrial, que sustituye los valores cristianos de la caridad, mansedumbre y amor al prójimo, por una corriente materialista en la que el motor es la adquisición de bienes materiales, dinero y posición social. En fin, Galdós analiza en Torquemada en la hoguera la realidad española desde un plano fundamentalmente ideológico, de raíz ética, que pone en tela de juicio la estructura socioeconómica existente e imputa en buena medida a la clase acomodada los fallos y los males que se ciernen sobre el país. 